\title{
人体筋の力・速度関係に及㴗す短縮前状態の影響
}

\author{
金子公 有*
}

（明和52年 7 月 4 日受付）

\section{The Effect of Different Previous States of Shortening on the Force-Velocity Relationship in Human Muscle}

\author{
Masahiro Kaneko \\ The Laboratory of Exercise Physiology \\ Osaka College of Physical Education
}

\begin{abstract}
The force-velocity relationships were determined on six adult males by two methods providing different previous states of shortening; the maximum elbow flexions were made against a gived load from (a) the state of isometric contraction (quick release method: QR) and from (b) the resting state (after load method: AL). The apparatus used was basically identical with one used by Wilkie (1950). The loads were prescribed by the fractiens (\%) of isometric tension $\left(P_{0}\right)$ of the individual. The velocity was measured using a linear velocity transducer. The results obtained were as follows;

1) The velocities under the loads above $10 \% \mathrm{P}$ 。 were unexceptionally greater in $\mathrm{AL}$ when compared them intra-individually. On the contrary the maximum velocities with no weight were greater in $Q R$ with the exception of two subjects. Thus, the force-velocity relationship in $Q R$ was more concave than that in $A L ; a / P_{0}$ values in the mean were 0.43 and 0.26 for $A L$ and $Q R$, respectively.

2) The maximum mechanical power in $\mathrm{QR}$ was about $25 \%$ less than that in $\mathrm{AL}$.

3) The amount of action potentials during shortening, which was obtained by integrating the EMG of brachial biceps muscle with surface electrodes, did not show any considerable differences between $Q R$ and $A L$ methods.

1) The initial accelerations, from the onset to peak velocity, were always greater in $\mathrm{QR}$ due to less time occupied to reach its peak velocity.

5) Taking these results and references into consideration, it was discussed that the greater velocity in $A L$ might be in part due to an delayed recoil of elastic energy stored at an early stage of shortening, as in a whip.

(Masahiro Kaneko: The Effect of Different Previous States of Shortening on the ForceVelocity Relationship in Human Muscle. Jap. J. Phys. Educ., Vol. 22, No. 5, Jan. 1978, pp. 295 299)
\end{abstract}


力・速度成係 (force-velocity relationship) は 活動筋の動的特性を示す代表的な法則 性である

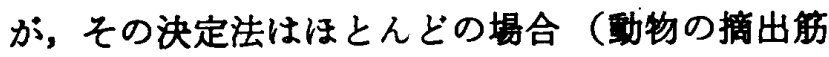
の場合)，等尺性張力が最大に達した時点で突 然 筋を短䈹させる方法（急速解放法 quick release method)によっている.しかしながら, 人体筋の力 ・速度関係を調べたWilkie (1950) ${ }^{8)}$ の実験では, 休息状態から直接一定の荷重に対して力を発揮す るとい 5 方法（以下, 後荷重法 after load method とい5）が採用されている.すなわち, 両方法の 間には短樎前状態が一方が等尺性収縮，他方が休 息状態とい5よ5に極端に相違している。筆者 $(1974$, p. 78) は) はかつて 1 被耠者につき両者の方 法で力・速度関係を調へ，急速解放法の方が同一 荷重に対して速度が低いことを稓察したが，もし む，このよ5な短縮前状態が確かに短縮速度の大 きさに影響を与えるものであるとすれば，筋収縮 特性に関して何らかの説明がなされなければなら ないと考え，本研究において急速解放法之後荷重 法による力・速度関係の差異を確かめるととも に，その要因を考察しょ5とした。

\section{〈方法〉}

健康成人男子 6 名 (20～24歳）（表 1）を被験者 として，図1の装四により実験した。すなわち， 被験者は椅座位で上腕を体側方の 水平台上に置い て固定し，时関節を $140^{\circ}$ から $70^{\circ}$ まで最大努力で 届曲する。このとき，手頸部のベルトとワイヤー を介して連結された長いレバー（a）が前腕とほぼ 平行状態で回転する. 同時に長いレバーと直角に 阫結した短かいレバー（b) 回枟し，问枟軸から $10 \mathrm{~cm}$ の点に吊された荷重（W）が车きあげられる。 浬度の椧州には，無低抗電磁コイル（Scheivit?

\section{表 1 被法者の特徽}

\begin{tabular}{|c|c|c|c|c|c|}
\hline Subject & $\begin{array}{c}\text { Age } \\
\text { (years) }\end{array}$ & \begin{tabular}{|l} 
Height \\
$(\mathrm{cm})$
\end{tabular} & $\begin{array}{c}\text { Weight } \\
(\mathbf{k g})\end{array}$ & $\begin{array}{l}\text { Forearm } \\
\text { length } \\
\text { (cal) }\end{array}$ & $\begin{array}{l}P_{0 *}^{*} \\
(k g)\end{array}$ \\
\hline $\mathrm{O} \mathrm{J}$ & 21 & 174 & 56 & 24.2 & 23.8 \\
\hline S K & 21 & 164 & 55 & 24.0 & 25.1 \\
\hline $\mathbf{Y M}$ & 20 & 154 & 60 & 23.2 & 30.4 \\
\hline Y D & 21 & 179 & 81 & 26.5 & 35.9 \\
\hline $\mathrm{KN}$ & 20 & 176 & 70 & 25.3 & 42.4 \\
\hline MS & 24 & 175 & 71 & 25.4 & 45.3 \\
\hline
\end{tabular}

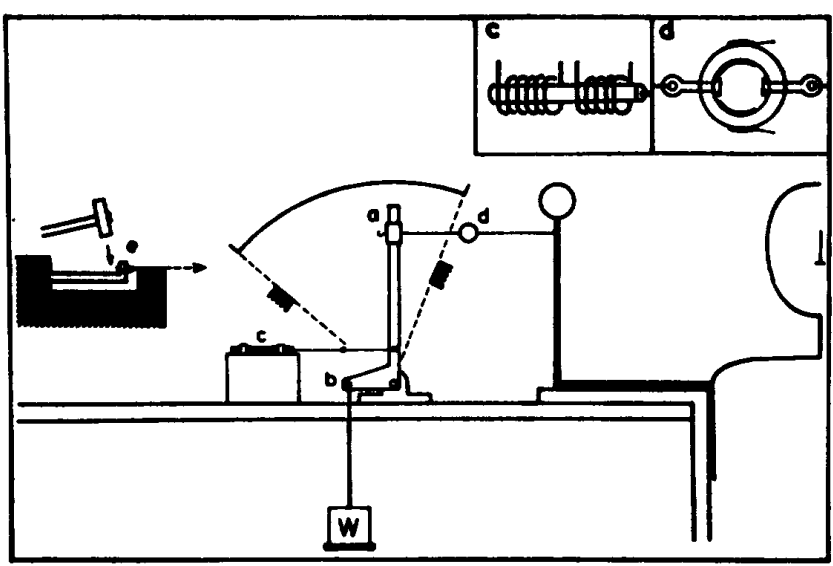

図1实方法（説明本文）

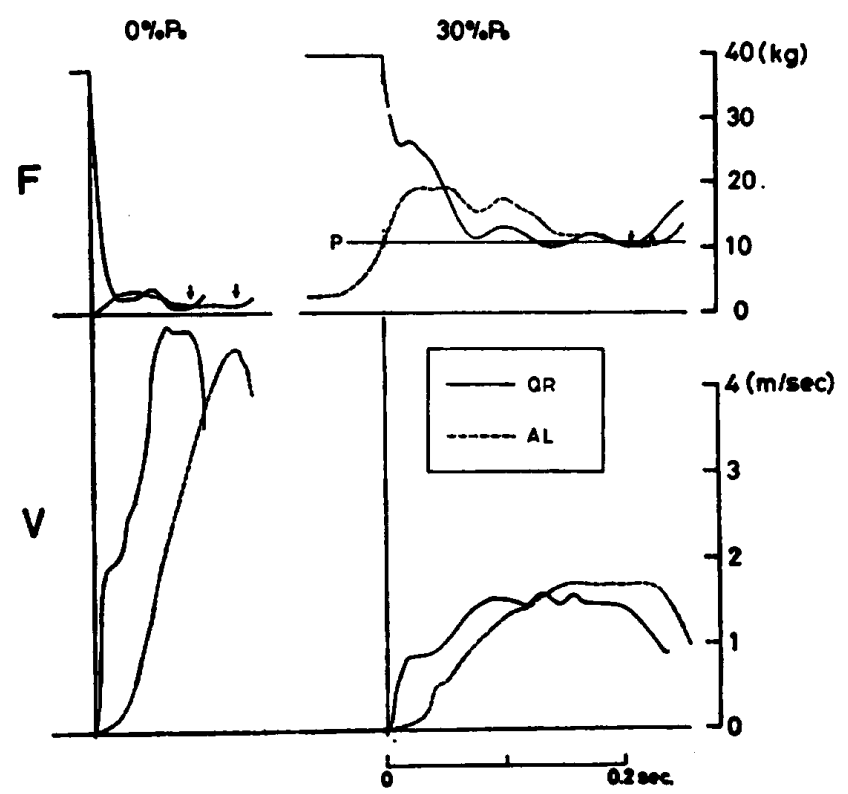

因2 刍速解放法（QR）と後荷重法（A）の力 曲楾 (F) と速度曲楾 (V) の比制

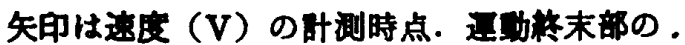
カの上昇，遭度の低下とは，長いレパー（a） がストッパー（スポンジ付）下当たる除のアー チファクトが含まれている.

製，7L6VT-2）を用い，これを長いレバーの回枟 帆から $6 \mathrm{~cm}$ の高さにとりつけ，时届曲全過程の瞬 時速度を記録し（図 2 火記録例)，肘関節角 $90^{\circ}$ て の速度（ほぼ最高速度）を誖みとって，手頸部て の速度に换算した．なお，実唤の前後に，コイル 内の磁石棒を自由落下させ，重力加速度の積分に よる速度変化をすとに速度記録を较正した。また レバー(a)と手顒部間のワイヤーにストレンゲー

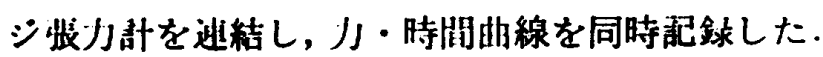
後攸禹法では，長いレパーが $140^{\circ}$ の位置でスト 
ッパーにより支えられた状怒から，最大努力で时 を届曲する，他方，急速解放法の場合は，図 1 (e)K示したように，ワイヤーによって長いレパ 一を $140^{\circ}$ の位国で固定し，被検者の等尺性筋力が 最高になった時点でピンをたたきワイヤーを解放 した。ただし被験者には时屈曲が完了するまで最 大努力を発揮するよう示棵した。荷重は各被験者 の等尺性最大施力（ $\mathrm{P}_{0}$; 时関節角 $90^{\circ}$ で测定）の $10,20 ， 30 ， 40,50,60 \%$ を決め，各荷重で怪い方 から 3 回ずつ, 重い方から 3 回ずつ（series and reverse) 测定し， 6 回試行の平均值を得て個人の 成粠とした。なお，荷重をぜロ $\left(0 \% \mathrm{P}_{0}\right)$ にして， 叞大速度 $\left(\mathrm{V}_{0}\right)$ を同样の試行により湘定した。

\section{〈结果と考家〉}

上跽の方法で得られた力（または荷重；P）と 速度（V）の関係を図 3 にプロットした。ここで, 最大筋力 $\left(\mathrm{P}_{0}\right)$ と前腕長（1）における個人差を 消去するため，力を最大筋力に対する割合 $\left(\% \mathrm{P}_{0}\right)$ に，速度を前腕長 (1)K対与る割合 $(1 / \mathrm{sec})$ Kそ れそれ変換し，個人別に記号を変えて示した．各 個人について後荷重法（白記号）と急速解放法（黒 記号）の速度を比较すると，無荷重を除くすべて の荷重条件ですべての被匼者が後荷重法において 高い值を示した。これに対して無荷重下の最大速 度では逆に，最大筋力の最る低い2 被検者（SK， O J ）を除く他の 4 名が急速解放法においてょり 高い值を示した。困3の手项部における力（また は負荷）・速度曲線（双曲線）は，Hill の特性方 程式 (s) :

$$
(P+a)(V+b)=\left(P_{0}+a\right) b
$$

（たたしPは力または負荷，Vは速度，Poは等尺 性最大能力，a， b は定数）によったるのである が，このための定数 $\mathrm{a} ， \mathrm{~b}$ は，全被験者の $\mathrm{P}$ と（ $\mathrm{P}_{0}$ 一P)/Vの間の回烚方程式を得て決定した。なお 手頸部における負荷（load）は力に一致し，また 测定された速度と対応する時点のるの故，機沩的 パワー（PV)を，(1)に基く

$$
P V=b P\left[\left(P_{0}+a\right) /(P+a)-1\right]
$$

に上って決定し，この関係曲稳再同中に加えた。 なおこのパワーは，相対負荷 $\left(\mathrm{P} / \mathrm{P}_{0}\right)$ が,

$$
P / P_{0}=\left(a / P_{0}\right)\left(\sqrt{1+} \bar{P}_{0} / a-1\right)
$$

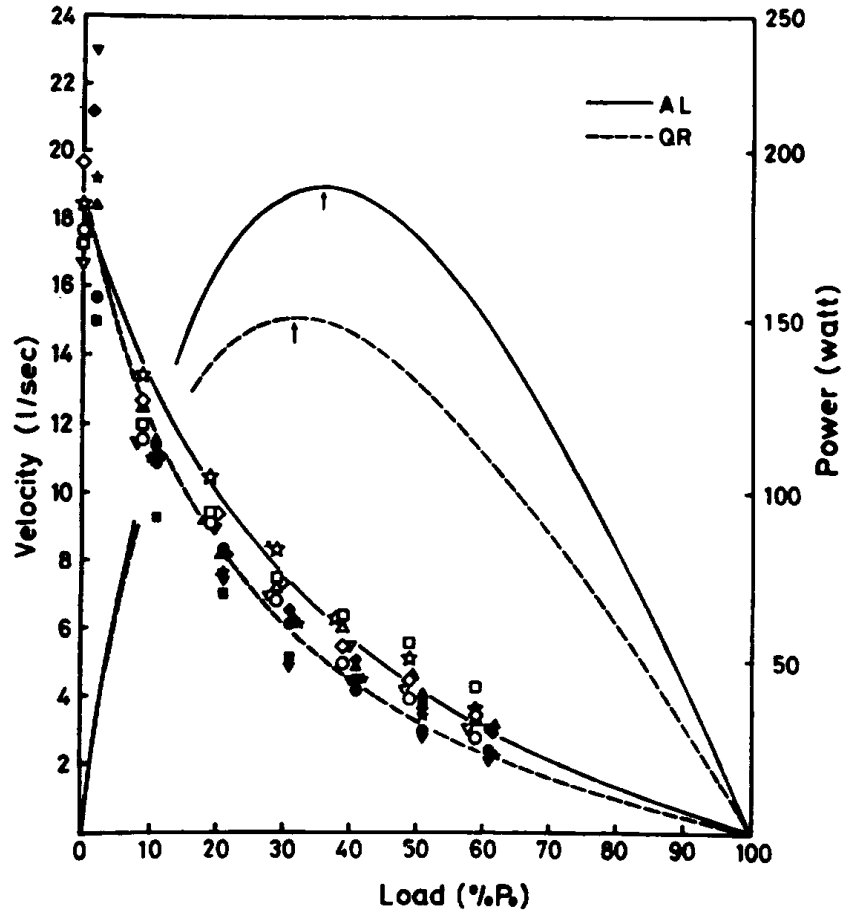

因 3 程々角荷（力）年件下で後荷重法（自記号 と実楾：A L) と急速解放法（黑祀号と破腺： QR) の速度の的係

負荷は相対負荷 $\left(\% \mathrm{P}_{0}\right)$ ), 前新速度は長 (1)

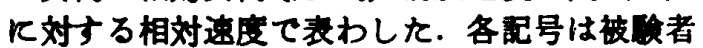
飞対応する $(\mathrm{O}: \mathbf{O} \mathbf{J}, \square: \mathbf{S}, \triangle: \mathbf{Y}, \triangle$, 山 $: Y D, \diamond: K N, \nabla: M S)$ ，負荷・速度 曲線（凹型）および負荷・パワー曲線（凸型） は Hill の式により措いた。

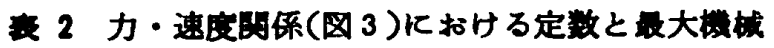
的パワー

\begin{tabular}{l|c|c|c|c}
\hline \multicolumn{1}{c|}{ Method } & a & b & a/P & $\begin{array}{c}\text { PVmax } \\
\text { (watt) }\end{array}$ \\
\hline After load & 14.5 & 1.95 & 0.43 & 189.1 \\
Quick release & 8.8 & 1.21 & 0.26 & 151.0 \\
\hline
\end{tabular}

注：定数a，bの単位は，それぞれkg，m/secである.

のとき最大となる。これら平均曲線に対応する数 值を表 2 K示したａ/ $\mathrm{P}_{0}$ の定数が示すよ5に，急 速解放の方が曲線の曲が著しく，最大パワー (PVmax) の出現する負荷 $\left(\mathrm{P} / \mathrm{P}_{0}\right)$ が小さい.

このような差異を生ずる原因として，まず力学 的な锶点から力と速度の時経過を锶察するため, 図2にその典型例をあげた。荷重を与えた場合の 他の記録は，持続時間と振幅の差を除けげ゙,急速解

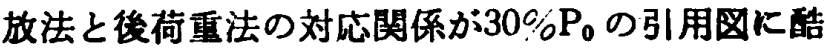
似していた。無荷重 $\left(0 \% \mathrm{P}_{0}\right)$ 条件における力曲 
家 3 各目何(力)条件下での平均加速度 （全被的者の平均之标算偏差）

\begin{tabular}{r|r|r|r|r}
\hline $\begin{array}{c}\text { Load } \\
\left(\% \mathbf{P}_{0}\right)\end{array}$ & \multicolumn{2}{|c|}{ After load } & \multicolumn{2}{c}{ Quick release } \\
\hline & $\overline{\mathbf{x}}$ & S.D. & \multicolumn{1}{c|}{$\overline{\mathbf{x}}$} & \multicolumn{1}{c|}{ S.D. } \\
\hline 0 & 41.3 & 5.79 & 66.7 & 17.67 \\
10 & 23.5 & 3.74 & 33.0 & 2.58 \\
20 & 19.1 & 1.87 & 21.2 & 2.54 \\
30 & 11.5 & 1.79 & 15.1 & 2.88 \\
40 & 8.5 & 1.08 & 11.8 & 1.69 \\
50 & 6.5 & 1.00 & 9.5 & 1.62 \\
60 & 4.6 & 0.94 & 6.3 & 1.08 \\
\hline
\end{tabular}

数值 $\left(\bar{x}\right.$, S.D.) の単位は $\mathrm{m} / \mathrm{sec}^{2}$.

線は，特に短縮初期において急速解放法の方が著 しく大さく，これが䅂末速度を高めた值接的要因 であろ5と思われる。一方，荷重条件下での終末 速度が後荷重法においてより大きいことの直接的 原因は，短籍後半における大きな力の発生にある と言える。市た, 速度曲線から短縮初期（短縮閏 始から最望速度まで）の平均加速度を調べると， 全被験者において，どの負荷条件であ急速解放の 方が大きな值を示す（表 3 に平均值を示した）。 の結果は，図 2 の速度・時間曲楾からも推定され るとおり，急速解放の方が最高速度に達するまで の時間が短かいことに起因している。この点に関 連して Wilkie $\left.(1950)^{8}\right)$ は，休息からの短縮（後 荷重法）では，直列弾性要素があるために速度曲 楾の文り上りが遅れることを訓明している。また Hill (1950)はは筇が休息状態から急激に短縮す る場合に淔列弾性要素に眝えられる弾性エネルギ 一は，最終速度を高めるのに使用され，収縮要素 だけによる場合より大きな速度を生じさせる」と 遮へている. Cavagna et al. (1968)" の強制伸張 による場合はど頙著でないにしても，本研究の胞 届曲においても，前腕やレバーの慣性と荷重に抗 して，後荷重法の短樎初期に弾性エネルギーが詝 えられここれが運動の耛末時に向けて放出され速 度を高めたと考えることは，それはど不目然では ない上5 K思われる。一方の念速解放法の場合に む，弾性エネルギーの眝荿は等尺性収樎の状態で 起こっているはずである．しかしそれは力曲線と 速度曲線のパターン(図 2)からみて，短樎初期に 放比されたと考えられる。無目荷条作を除くすべ
ての荷重条件下での速度が，後荷重法の方で大き くなる原因は，弾性エネルギーの貢献が短䋨の運 い時点で(あたかる战のように)現われるところに あったのではないか，最大速度の差異もこの線に 沿って説明され得るよ5に思われる.すなわち，後 荷重法では無荷重であるために眝えられる弾性エ

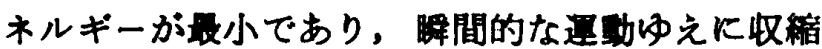
要秦の活功が十分に表出し難い，これに対して，急 速解放の揚合は収樎要素が短樎前からすでに最高 の活動状態（active state）にあり，また，Fenn (1938) 名) が論じているよ5に, 前腕は $\mathrm{d} \omega / \mathrm{dt}=$

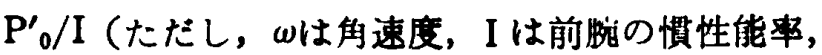
$\mathrm{P}_{0}^{\prime}$ は短樎前の等尺性筋力のモーヘント）の牦加 速度で発射されるため, 最大速度 $\left(\mathrm{V}_{0}\right)$ が急速解 放の方で大きくなる可能性が考えられる。このよ 5な説明は矛盾がない上5に思われるが，あくま でも推論であって碓たる証肳はない。

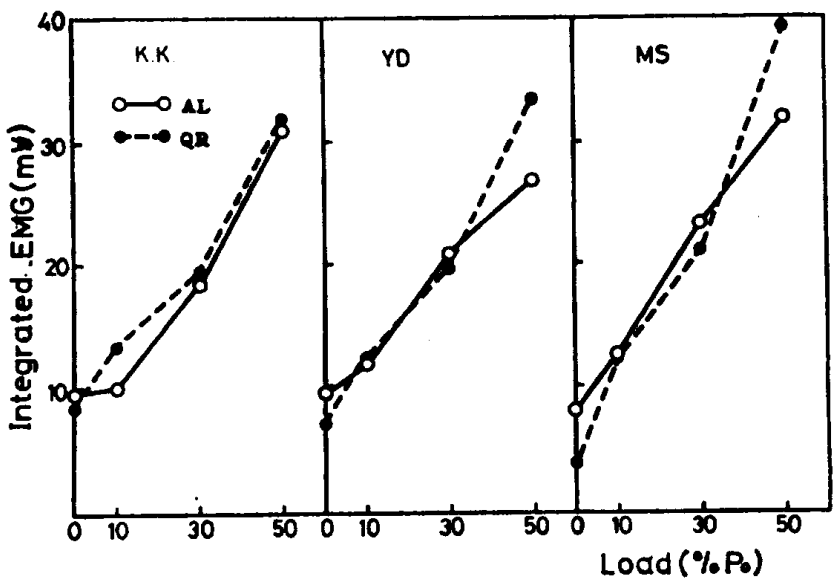

図4後荷重法（○；A L ） と急速解放法（○；Q R）の短樎中における上腕二頭肍の第放電皘分 值の比攻

次に，こ5した小学的現家の背後にある少:理的 要因として，まず筋の興至の度合が後荷重法と息 速解放法において相连したのではないかとい5知

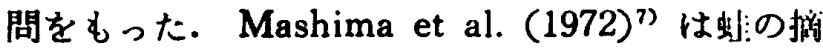

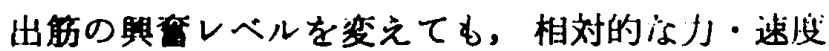
関係に組織的な变化は起こらないとしているが， 人体筋においては随意収縮であるために，族に到 達する刺激条件が相连する可能性が烧克られるか らである。そこで3名の被唋者を算作為に描州し，

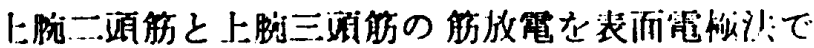

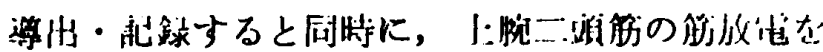


積分回路を通して積分した。 その結果，急速解放 による短樎時の場合，被硂者（MS）の 0 40\% $\mathrm{P}_{0}$ の負荷において，また被験者（KN）では０\% $\mathrm{P}_{0}$ のみにおいて，それそれ上腕二頭筋の施放電に 休止期 (silent period) が锶察された.しかしな がら，短樎全過程の筋放奄量（稳分值）には，四 4 に示したとおり一定した明䀧な差異は認められ ずむしろ急速解放の方が無荷重下で少なく，60 $\% \mathrm{P}_{0}$ 下で大きいこの傾向は速度の成丧とは逆で あって，速度差の原因の説明にはならない。この

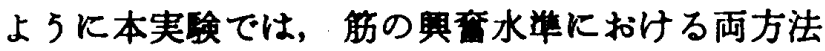
間の差を指摘することはできなかったが，この点 に関してはなお詳細な筋電図分析が必要のよ5に 思われる。

\section{$<$ 票的>}

1）七トの时届筋群の力 ・ 速度関係 $(\mathbf{P} \cdot \mathrm{V}$ 関係) を成人男子 6 名について次の 2 つの方法で調 ○ た：(1)休息状態から（後荷重法）(2)等尺性収縮か ら（急速解放法），それそれ最大努力で时関節を 届曲する，装置はWilkie (1950) のものと同じ機

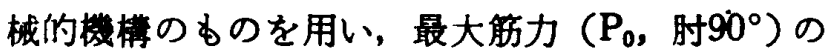
$\%$ で荷重を与えた。速度（时 $90^{\circ}$ ) は直楾型速度 検出器によった。

2） $10 \% \mathrm{P}_{0}$ 以上の負荷に対する速度は，全被䀫者 において急速解放法の方が低く，無荷重下の最大 速度では逆に，2名を除く全員において急速解放 法の方が高い，したがって力・速度関係は急速解 放法の方がより曲 $\left(\mathrm{a} / \mathrm{P}_{0}\right.$ 比が小さい) し, 最大 パワーの出現する負荷 $\left(P / P_{0}\right)$ が小さい。 また， 最大パワーは急速解放法の方が約 $25 \%$ 小さい。

3）表面電極法により記録された上腕二謴筋の放 電星（短樎全過程の栍分値）には，润方法間に明 らかな差が認められない。

4) 初期加速度（短樎開始から最高速度まで）は急 速解放法の方がすべての負荷で大きく，これは最 高速度に達するまでの時間が短かいことに因る。

5）これらの結果と文献から，後荷重法に打ける 速度の優位は，短縮初期に眝えられる弾性エネル ギーの短縮後半における放出（㵵の上5な知き） によるという推論を犃みた。
本研究をすすめるに当たり，真島英俉数授（㮌天堂大 ・医・生理）の喛かい数励とアドバイをいただいた。 また大阪体育大学の㴊本隆文氏の献身的な助力を得た。 記して深新の意を表します。

\section{引用文辝}

1) Cavagna, G.A., B. Dusman and R. Margaria : Positive work done by a previously stretched muscle. J. Appl. Physiol. $24: 21-32,1968$.

2) Fenn, W.O. and B.S. Marsh: Muscular force at different speeds of shortening. J. Physiol. $85 ; 277-297,1935$.

3) Fenn, W. O.: The mechanics of muscular contraction in man. J. Appl. Physics 9 ; 165177, 1938.

4) Hill, A.V.: The series elastic component of muscle. Proc. Roy. Soc. B137 : 273-280, 1950.

5) Hill, A.V.: The heat of shortening and dynamic constants of muscle. Proc. Roy. Soc. B126 : 136-195, 1938.

6）金子公有：発的パワーからみた人作胼のダイナミ クス. 杏林费院， 1974.

7) Mashima, H., K. Akazawa, H. Kushima and K. Fujii: The forceload-velocity relation and the viscous-like force in the frog skeletal muscle. Jap. J. Physiol. 22 : 103-120, 1972.

8) Wilkie, D.R.: The relation between force and velocity in human muscle. J. Physiol. 110: 249-280, 1950. 